\title{
Перец сладкий - стратегия роста
}

\section{В.В. Огнев, Т.В. Чернова, А.Н. Костенко, Н.В. Гераськина, Н.А. Полтавский}

Представлены современное состояние и перспективы производства и потребления перца сладкого в России. Показан вклад селекции в совершенствование сортимента перца сладкого. Подчеркнута ведущая роль сортов и гибридов этой культуры в росте урожайности и повышении качества продукции. Дано описание перспективных $F_{1}$ гибридов перца сладкого селекции Агрохолдинга «Поиск».

Ключевые слова: перец сладкий, производство, потребление, селекция, сортимент, гибриды.

$\Pi$ опулярность перца сладкого в России за последние годы заметно выросла. Потребление свежих плодов стало круглогодичным, более разнообразным стал и ассортимент консервированной продукции Связано это с высокой пищевой ценностью культуры, изменением в лучшую сторону рациона питания людей, пропагандой среди населения здорового образа жизни [1]. Перец сладкий - это настоящий поливитаминный концентрат с выраженной антиоксидантной активностью, широко используемый в функциональном питании. Его плоды пригодны для непосредственного употребления в пищу и являются ценной добавкой, улучшающей питательную ценность, вкус и аромат самых разнообразных блюд домашней кулинарии, овощных, рыбных и мясных консервов [2].

В связи с ростом собственного производства наблюдается и снижение импорта плодов перца из-за рубежа. Основными иностранными поставщиками перца до недавнего времени были Нидерланды, Польша, Испания и Израиль. После введения продовольственного эмбарго импорт перца только в 2016 году снизился на 18,3\% по отношению к 2015 году. На этом рынке сохранил свои позиции только Израиль [3]. В зимних теплицах перец сладкий не рассматривается как ведущая культура, а относится к сегменту нишевых овощей, доля которых не превышает 3\%. Сдерживающий фактор здесь - меньшая популярность культуры у широких слоев потребителей, более низкая урожайность при сравнительно высоких затратах на производство, отсутствие возможностей выращивать перец в период на- ибольшей востребованности (в зимние месяцы), а также сильная конкуренция открытого и утепленного грунта в летний период [4].

В то же время, производство перца сладкого в открытом и утепленном грунте в сильной степени диверсифицировано, что не позволяет обеспечить бесперебойное снабжение развивающейся сетевой торговли, потребности которой по таким культурам как перец и баклажан превышают 300 тыс. т в год. Решить проблему можно как за счет развития круглогодичного выращивания культуры в зимних теплицах, так и за счет расширения производства в весенних теплицах, с переводом туда значительной доли производства из открытого грунта. Это позволит сократить импорт плодов перца и добиться самообеспечения в этом сегменте овощного рынка [4, 5]. Наряду с решением ряда технологических вопросов, связанных с расширением площадей возделывания перца в открытом и защищенном грунте, таких как внедрение светокультуры, усовершенствование систем питания, защиты растений, формировки и подвязки растений, возникает и проблема повышения урожайности и качества продукции [5, 6, 7].

Практика выращивания перца сладкого показывает, что ведущую роль в росте урожайности и повышении качества продукции играет правильный выбор сорта. Освоение в производстве новых генотипов позволяет не только повысить валовые сборы продукции, но и снизить издержки производства за счет более эффективного использования новыми сортами и гибридами агроклиматических ресурсов, удобрений, воды, средств защиты растений при одновременном снижении затрат человеческого труда [8].

Результаты многолетних исследований подтверждают заметные преимущества при выращивании гибридов первого поколения в сравнении со свободноопыляющимися сортами. Поэтому в России наметилась явная тенденция к переходу от создания сортов к селекции гетерозисных гибридов. Прежде всего это касается коммерческих гибридов, выращиваемых для товарного производства в защищенном грунте. Но и в открытом грунте на значительных площадях тоже выращивают гибриды. Это стало возможным благодаря совершенствованию технологий выращивания, позволяющих сократить расход семян на посев $[8,9]$.

Большое разнообразие условий выращивания коммерческих гибридов перца сладкого и направлений использования получаемой продукции предполагает, что создаваемый сортимент культуры должен быть также разнообразным по морфологическим и хозяйственно полезным признакам и обладать комплексом этих признаков и свойств, что проще обеспечивать при селекции гетерозисных гибридов первого поколения [9, 10].

Целью исследований, проведенных в Селекционно-семеноводческом центре «Ростовский» Агрохолдинга «Поиск» в 2010-2019 годах, было изучение исходного материала и создание на его основе гетерозисных гибридов перца сладкого для условий юга России.

Исследования проводили на полях и в весенних теплицах в селекционном центре, и в хозяйствах различных зон производства культуры перца сладкого по стандартным методикам [11]. Применяли принятые в регионе технологии выращивания перца сладкого. В работе использовали собственный селекционный материал и образцы мировой коллекции ВНИИР им. Н.И. Вавилова, лучшие коммерческие гибриды иностранных фирм. 
Любая селекционная программа базируется на изучении, подборе и создании исходного материала, соответствующего поставленной цели. Основной задачей при этом было получение исходного материала с комплексом заданных признаков и свойств. Наибольший интерес при создании линий для селекции на гетерозис представляют иностранные гибриды и местный материал. Образцы иностранной селекции - источник высокой продуктивности и товарности, крупноплодности, а местный материал обладает такими важными признаками, как устойчивость к болезням увядания и неблагоприятным климатическим и почвенным факторам (жара, засуха, засоление и т.п.). Как правило, полученный линейный материал обладает высокой комбинационной способностью, что важно при селекции на гетерозис.

Разнообразие полученных линий по морфологическим и хозяйственным признакам позволило создать несколько перспективных гибридов. Первоначально гибриды создавались на фертильной основе, что было вполне оправдано при ограниченном спросе на новинки. По мере расширения спроса возникла потребность в удешевлении процесса семеноводства. Здесь самая трудоемкая и дорогостоящая операция кастрация цветков. У сладкого перца растрескивание пыльников происходит еще в бутонах, а это создает определенные сложности с поддержанием должного уровня гибридности полученных семян. Часть из них может завязаться от самоопыления, произошедшего еще до кастрации

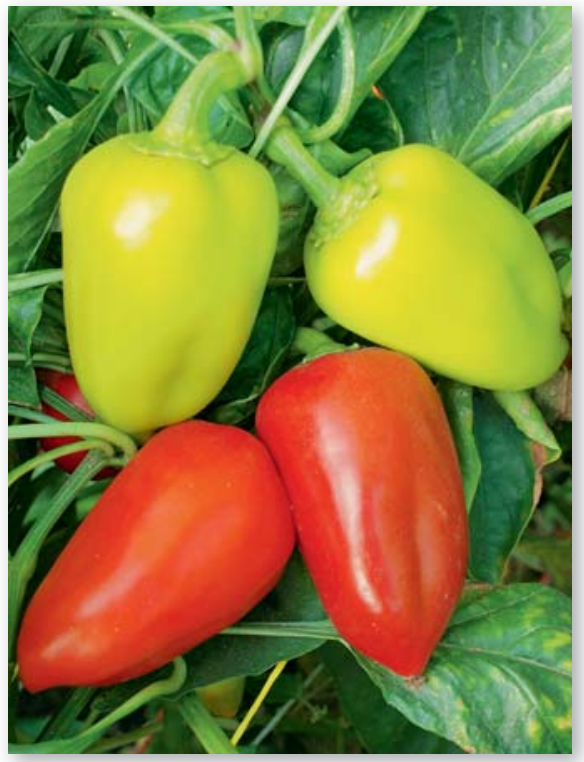

Рис. 1. $F_{1}$ Император цветка. Контролируемое скрещивание возможно только при использовании в селекционном процессе мужски стерильных форм. Это может быть либо ядерная мужская стерильность, которая была использована при создании гибридов $F_{1}$ Император и $\mathrm{F}_{1}$ Семко юбилейный, или цитоплазматическая мужская стерильность, которая легла в основу получения таких гибридов, как $F_{1}$ Фишт, $F_{1}$ Темп, $F_{1}$ Белогор и др. Второй тип стерильности более надежен при массовом семеноводстве. Именно этот тип стерильности использован нами как основной.

Для получения гибридов на основе ЦМС необходимо создание собственно стерильной женской линии и ее фертильного аналога - закрепителя стерильности. В качестве отцовской линии выступают линии-восстановители фертильности. Наибольшие проблемы возникают при получении именно этих линий. Только несколько сортов оказались пригодными для этих целей. Остальные пришлось создавать на их основе и используя отборы из имеющихся гибридов на стерильной основе. Банк линий постепенно накапливается и дает возможность создавать гибриды с самыми разными признаками, в том числе востребованными в производстве в настоящее время.

Особый интерес в производстве проявляется к нескольким новым гибридам, спрос на семена которых постоянно растет. К ним относятся такие гибриды Агрохолдинга «Поиск», как $F_{1}$ Император, $F_{1}$ Илона, $F_{1}$ Байкал, $F_{1}$ Белогор, $F_{1}$ Атлет, $F_{1}$ Премьер, $F_{1}$ Альянс и $F_{1}$ Фараон.

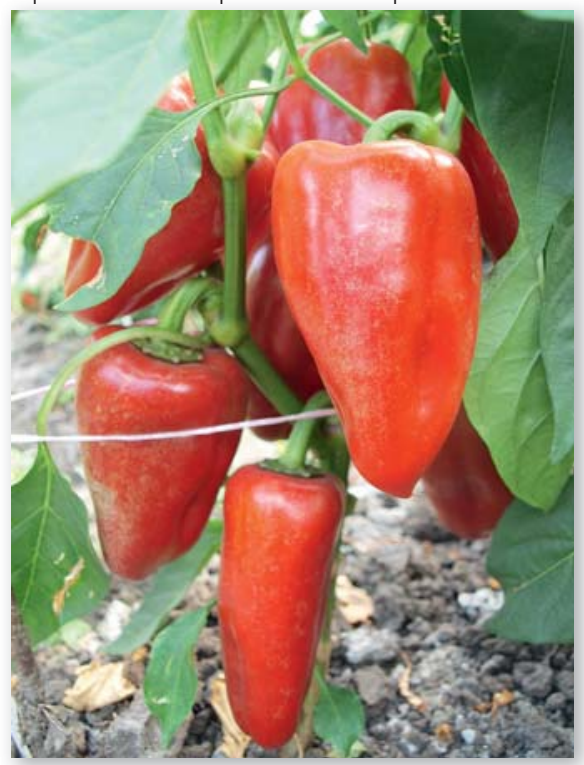

Рис. 2. $F$ Байкал
Самые ранние из этой группы гибридов это $F_{1}$ Белогор, $F_{1}$ Атлет и $F_{1}$ Премьер, другие созревают несколько позже, но также относятся к среднеранней группе. Различаются гибриды по морфологическим и хозяйственным признакам, что позволяет подобрать более подходящий для конкретных условий выращивания. Практически все эти гибриды пригодны для возделывания как в открытом и утепленном грунте, так и в весенних теплицах.

Наиболее старый и хорошо известный производственникам гибрид $F_{1}$ Император (рис. 1). Плоды этого гибрида достигают технической спелости на 94-100 день от массовых всходов. Плоды имеют конусовидную форму, они крупные, выравненные по размерам. Окраска в технической спелости светло-зеленая, в биологической - красная. Масса плода 130-150 г, толщина стенки достигает 6-7 мм. Растения компактные, среднего размера, слабо поражаются болезнями увядания, устойчивы к вирусу табачной мозаики. Урожайность в теплицах со-

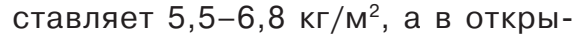
том грунте - более 70 т/га. Плоды достаточно лежкие и хорошо переносят транспортировку на большие расстояния, сохраняя высокую товарность. Вкус свежих плодов отличный, с приятным перечным ароматом. Плоды пригодны для свежего потребления, домашней кулинарии и консервирования. $F_{1}$ Император - это один из самых надежных в производстве гибридов со стабильной урожай-

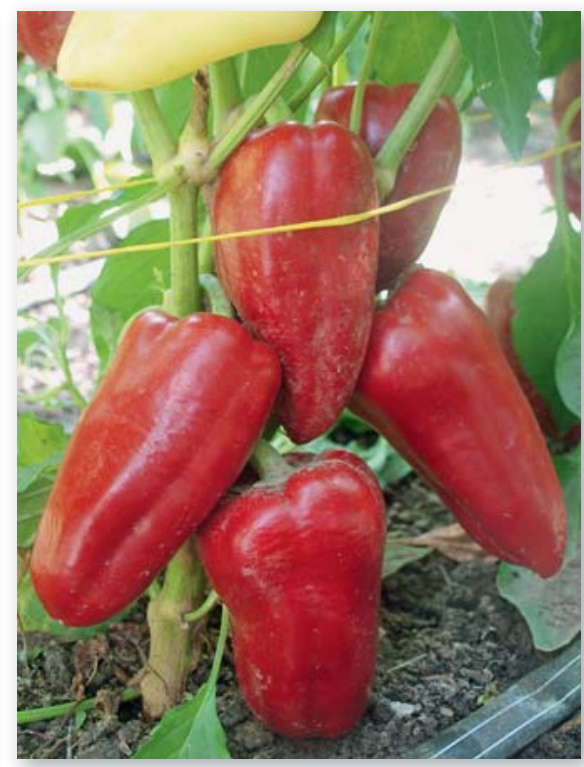

Рис. 3. $F_{1}$ Белогор 


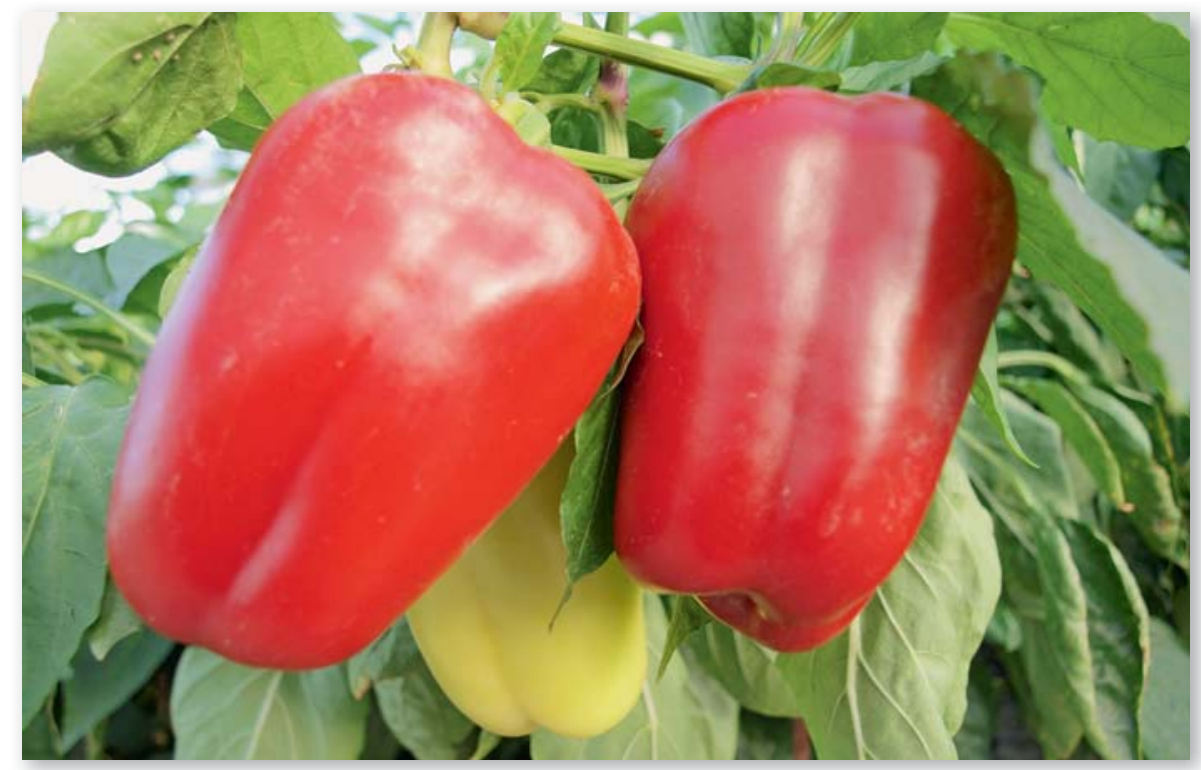

Рис. 4. $F_{1}$ Фараон

ностью в самых разных условиях выращивания.

Гибрид $F_{1}$ Байкал (рис. 2) coзревает на 95-105 сутки от массовых всходов. Плоды этого гибрида плотные, толстостенные, массой 180-220 г, конической формы, имеют в технической спелости светлозеленую окраску, а в биологической - ярко-красную. Плоды пониклые, крупные, хорошо завязываются в жару. Растения гибрида мощные, хорошо облиственные, что предохраняет плоды от солнечных ожогов. Урожайность в весенних теплицах превышает 6 кг/м², а в открытом грунте достигает 80 т/га. Гибрид ус-

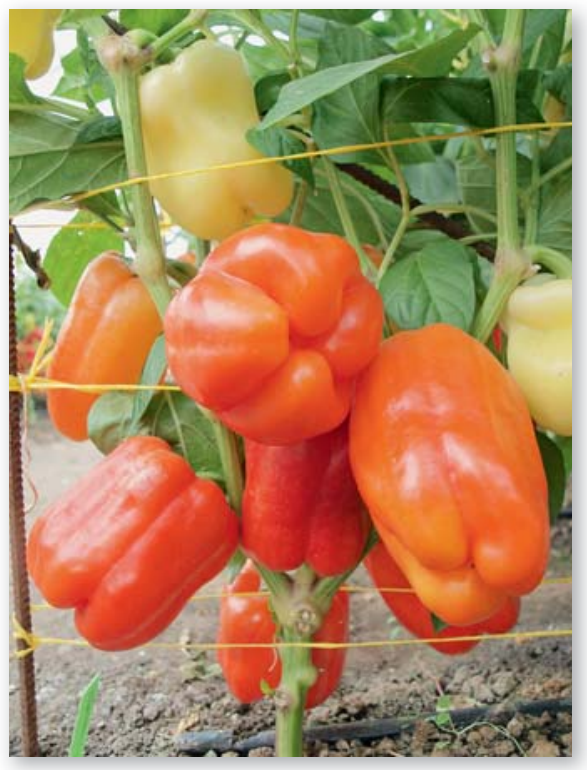

Рис. 5. $F_{1}$ Альянс тойчив к болезням увядания и вирусу табачной мозаики. Благодаря отличной лежкости и транспортабельности легко переносит транспортировку на большие расстояния. Рекомендуется для потребления в свежем виде и различных видов переработки.

Гибрид $F_{1}$ Белогор (рис. 3) созревает одним из первых на 90-94 сутки от массовых всходов. Широко используется для раннего производства под временными укрытиями. Имеет конусовидные пониклые плоды массой 120-140 г. Толщина стенки их 5,5-6,0 мм. Окраска в технической спелости светло-желтая, а в биологической - красная. Гибрид отличается хорошей завязываемостью

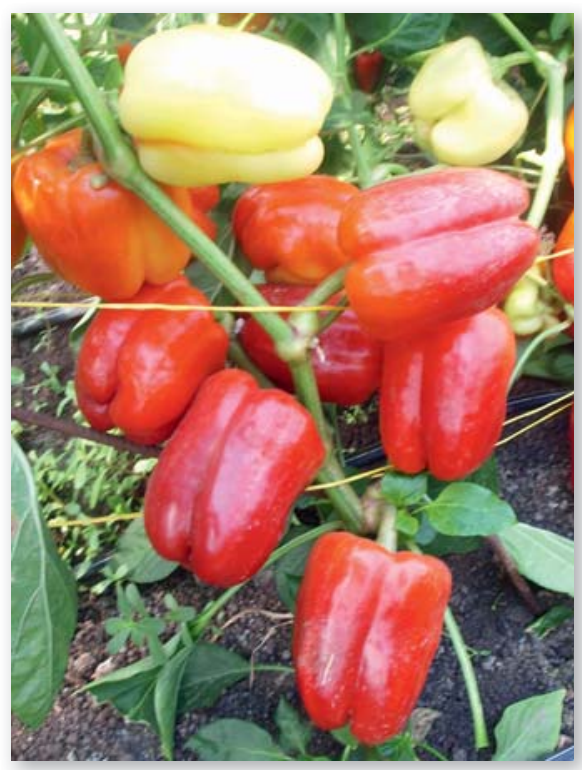

Рис. 6. $F_{1}$ Атлет и многоплодностью. Куст компактный, открытый. Урожайность превышает 4,5-5,0 кг/м². Устойчив к вирусу табачной мозаики. Плоды используют для свежего потребления и домашней кулинарии, пригодны для транспортировки.

Гибрид $F_{1}$ Фараон (рис. 4) созревает на 94-98 день от массовых всходов. Лучше всего удается в весенних теплицах. Имеет удлиненнопризмовидные, почти конусовидные плоды, отличающиеся высокой выравненностью по размерам и форме, массой 140-160 г. Окраска плода в технической спелости желтая, а в биологической - красная. Куст компактный, средней высоты, открытый. Урожайность в весенних теплицах составляет 6,2-7,5 кг/м². Плоды имеют приятный аромат и отличный вкус. Рекомендуется для свежего потребления и различных видов переработки.

Среди гибридов с призмовидной формой плода самым ранний $F_{1}$ Альянс (рис. 5). До технической спелости от массовых всходов проходит всего 90-95 дней. Плоды удлиненно-призмовидные, пониклые. Они крупные, массой 200-250 г. Окраска плодов в технической спелости ярко-желтая, в биологической - яркокрасная. Растения компактные, хорошо облиственные. Урожайность в весенних теплицах до 9 кг/м², в открытом грунте она достигает 90 т/га, используется в кулинарии.

Другой раннеспелый гибрид $F_{1}$ Атлет (рис. 6), имеет еще более компактные растения и отличается очень дружным созреванием плодов. Этот гибрид дает первые плоды на 90 день от массовых всходов. Образует плоды массой 90-140 г, призмовидные, пониклые, ярко-желтые в технической спелости и красные в биологической. Гибрид хорошо удается в ранней культуре под временными укрытиями. Плоды с сильным перечным ароматом, отличного вкуса. Рекомендуется для домашней кулинарии и свежего потребления.

Гибрид $F_{1}$ Премьер (рис. 7), в отличие от $F_{1}$ Атлет, созревает на несколько дней позже, но имеет более крупные кубовидные плоды массой 140-180 г. Одинаково хорошо растет как в открытом грунте, так и в весенних теплицах. Плоды в технической спелости желтые, а в биологической - ярко-красные, имеют привлекательный внешний вид, прекрасный аромат и вкус. Хорошо транспортируется на большие расстояния. Растения компактные, хорошо об- 


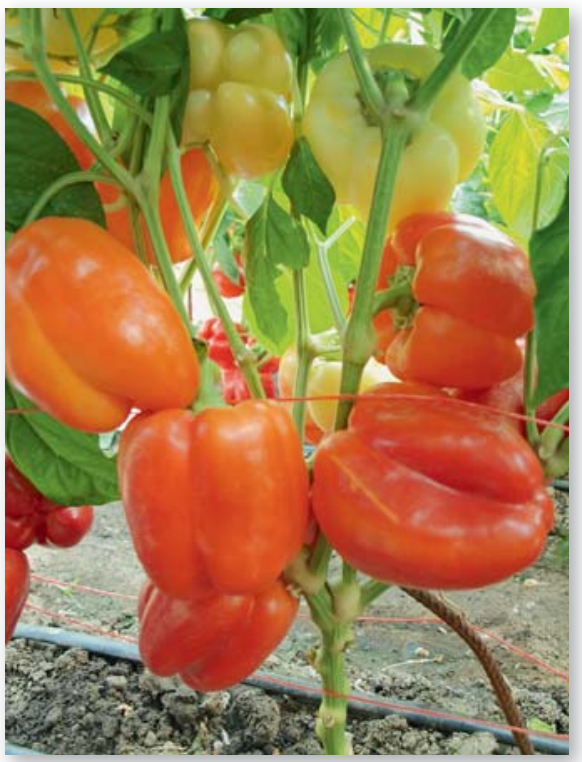

Рис. 7. $F_{1}$ Премьер

лиственные. Устойчив к болезням увядания. Урожайность в весенних теплицах 7,6-7,9 кг/м², а в открытом грунте свыше 70 т/га. Рекомендуется для потребления в свежем виде в технической и биологической спелости, для перевозки на большие расстояния.

Гибрид $F_{1}$ Илона (рис. 8) более позднеспелый. Первые плоды созревают на 100-110 день от массовых всходов. Формирует крупные призмовидные плоды массой 200-240 г с толщиной стенки более 7 мм. В технической спелости плоды имеют зеленоватую окраску, переходящую в светло-зеленую, а в биологической

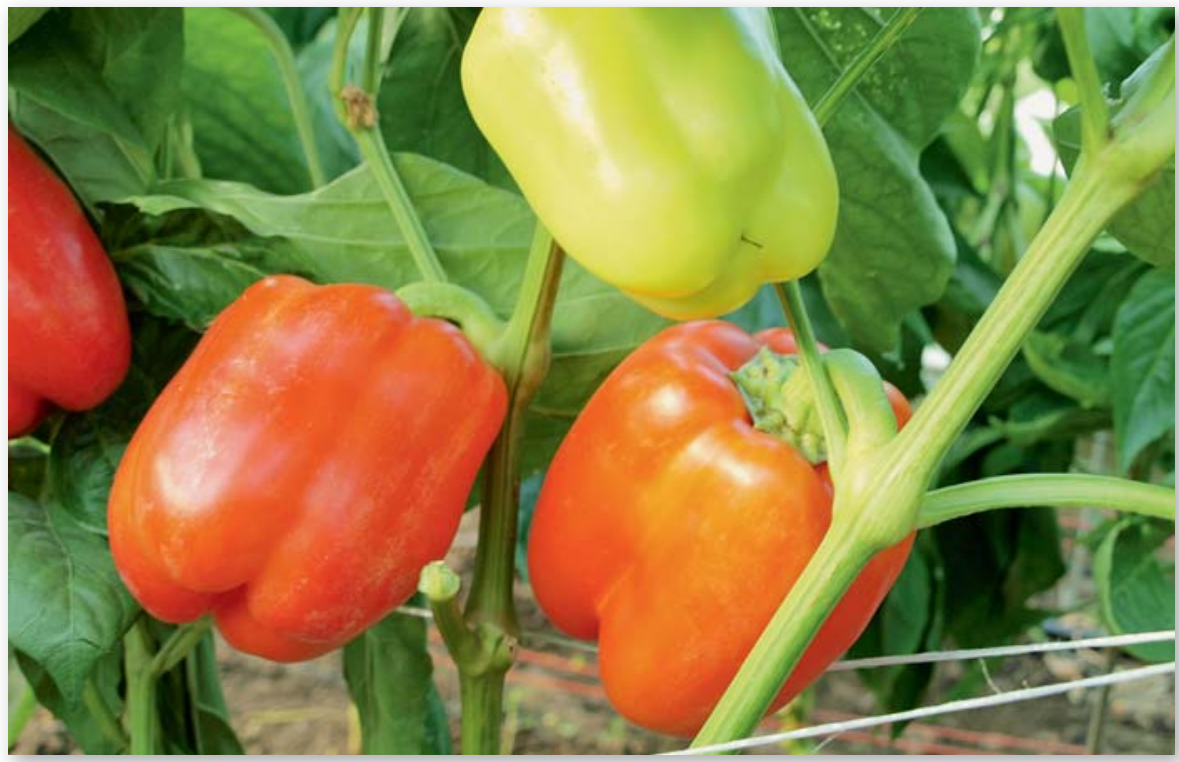

Рис. 8. $F$, Илона спелости - в ярко-красную. Растения компактные, хорошо облиственные. Хорошо растут как в открытом, так и в защищенном грунте. В весенних теплицах это один из самых урожайных гибридов, он дает 8,8-9,8 кг/ м², а в открытом грунте - более 80 т/га при высокой товарности. Плоды отличаются высокой лежкостью и транспортабельностью. Гибрид устойчив к болезням увядания и вирусу табачной мозаики. Предназначен для потребления в свежем виде, домашней кулинарии, перевозки на большие расстояния.

Таким образом, современный сортимент перца сладкого стал более разнообразным. Появились высокопродуктивные отечественные гибриды первого поколения, которые вполне конкурентоспособны с гибридами иностранной селекции. Российские селекционно-семеноводческие компании способны обеспечить импортозамещение в части снабжения товаропроизводящих хозяйств семенами высокопродуктивных коммерческих гибридов перца сладкого для открытого грунта и весенних теплиц. Широкий сортимент гибридов предлагает Агрохолдинг «Поиск», одна из ведущих частных селекционно-семеноводческих компаний России. Этот сортимент представлен самыми разнообразными гибридами перца с высокими потребительскими качествами. Селекция гибридов перца имеет в стране большие перспективы.

\section{Библиографический список}

1.Клименко Н.Н., Ховрин А.Н., Огнев В.В. Агрохолдинг «Поиск» - Селекция здоровья и долголетия //
Картофель и овощи. 2017. № 9. С. 8-10.

2.Пышная О.Н., Мамедов М.И., Пивоваров В.Ф. Селекция перца. М.: ВНИИсСОК, 2012. 248 с.

3.Королев С.В. О секретах успешной политики импортозамещения в сельском хозяйстве // Гавриш. 2017. № 1. С.4-6.

4.Добавим перца! Почему российские тепличники неохотно занимаются производством нишевых овощей // Гавриш. 2018. № 6. С.18-26.

5.Огнев В.В., Чернова Т.В. Перец в пленочных теплицах на юге России // Картофель и овощи. 2014. № 2. C.17-19.

6.Огнев В.В., Чернова Т.В. // Картофель и овощи. 2017. № 3. С. $16-19$.

7.Практика выращивания перца. М.: ООО Вильморин, 2015. $20 \mathrm{c}$.

8.Огнев В.В., Чернова Т.В., Гераськина Н.В. Исходный материал перца сладкого // Картофель и овощи. 2015 № 6. C. $14-15$

9.Огнев В.В., Чернова Т.В., Костенко А.Н., Полтавский Н.А. Гибриды перца сладкого для товарного производства // Картофель и овощи. 2018. № 10. С. 36-38.

10.Монахос Г.Ф. Селекция и семеноводство овощных культур в России на современном этапе // Вестник овощевода. 2012. № 1. С.15-21.

11.Литвинов С.С. Методика полевого опыта в овощеводстве. М.: Россельхозакадемия, ВНИиО, 2011. 648 с.

\section{Об авторах}

Огнев Валерий Владимирович, канд. с. - х наук, доцент, директор, ССЦ «Ростовский» Агрохолдинга «Поиск». E-mail: ognevvv@bk.ru Чернова Татьяна Викторовна, селекционер, ССЦ «Ростовский» Агрохолдинга «Поиск»

Костенко Александр Николаевич, канд. с. - х. наук, агроном-эксперт по испытаниям, Агрохолдинг «Поиск»

Гераськина Надежда Викторовна, канд. с. - х наук, селекционер, ССЦ «Ростовский» Агрохолдинга «Поиск»

\section{Полтавский Николай}

Александрович, аспирант,

Донской государственный аграрный университет

\section{Sweet pepper - growth strategy} V.V. Ognev, PhD, associate professor, director, Rostovsky breeding centre of Poisk Agro holding. E-mail: ognevvv@bk.ru T.V. Chernova, breeder, Rostovsky breeding centre of Poisk Agro holding A.N. Kostenko, $P h D$, agronomy expert in testing of Poisk Agro holding.

N.V. Geras'kina, PhD, breeder, Rostovsky breeding centre of Poisk Agro holding N.A. Poltavskii, postgraduate student, Donskoy State Agrarian University

Summary. Presented the current state and prospects of sweet pepper production and consumption in Russia. The contribution of breeding in the improvement of the sweet pepper variety is shown. The leading role of varieties and hybrids of this crop in increasing yields and improving product quality is emphasized. Description of promising hybrids sweet pepper breeding of Poisk Agro holding.

Keywords: sweet pepper, production, consumption, selection, variety, hybrids. 